\title{
O discurso como modo de existência/resistência: da literatura às manifestações nas ruas em 2018
}

\author{
The discourse as a form of existence/resistance: from literature to the 2018 street \\ manifestations
}

\author{
Karina Luiza de Freitas Assunção ${ }^{1}$ \\ Universidade Federal de Uberlândia - UFU \\ Universidade Federal de Goiás - UFG/PPGEL \\ karinalfa@gmail.com
}

\begin{abstract}
RESUMO: O presente texto tem como objetivo tecer uma reflexão sobre os sentidos que emergem de alguns enunciados do romance de José Saramago, juntamente com outros selecionados de cartazes que circularam em alguns movimentos sociais brasileiros arrolados no final do segundo semestre de 2018. Problematizaremos a constituição da subjetividade e sua relação com o poder, existência e resistência na contemporaneidade. As reflexões serão fundamentadas teoricamente na análise do discurso de linha francesa, nos estudos de Michel Foucault e Judith Butler. Concluímos que o funcionamento de um dado discurso é da ordem da guerra, como afirmou Foucault ao longo de suas pesquisas. Existir/resistir as suas nuanças se faz uma constante e se fundamenta em um movimento que não temos como prever os caminhos, muito menos os resultados, uma vez que será sempre da ordem do devir. Entretanto, resistir ao poder sempre, pois só assim existiremos enquanto sujeitos constituídos historicamente.
\end{abstract}

Palavras-chave: Discurso; Sujeito; Subjetividade; Poder; Resistência.

\begin{abstract}
This text aims at analyzing relations of power, resistance and constitution of subjects in contemporaneity. In order to achieve the proposed objective, were analyzed some utterances of José Saramago's novel, and other selected from posters of Brazilian social movements at the end of 2018 (second semester). The reflections will be theoretically based on French Discourse Analysis, studies of Michel Foucault and Judith Butler. The conclusion is that the functioning of a discourse is conflicting, as mentioned by Foucault throughout his research. To exist/resist in such discourses is constant and based on a movement that we cannot foresee forms and results, it will always be a devir (become). However, we must always resist power, since it is the only way to exist as historically constituted subjects.

Keywords: Discourse; Subject; Subjectivity; Power; Resistance.
\end{abstract}

\footnotetext{
${ }^{1}$ Professora Adjunta da Universidade Federal de Uberlândia - UFU/ESEBA e Professora Colaboradora do Programa de Mestrado em Estudos da Linguagem da Universidade Federal de Goiás - Campus Catalão. Doutora em Estudos Linguísticos pela Universidade Federal de Uberlândia - UFU.
} 


\section{Existir/resistir...}

A arte é o que resiste: ela resiste à morte, à servidão, à infâmia, à vergonha (DELEUZE, 1992, p. 219).

Deleuze (1992), respondendo a uma questão proposta por um entrevistador, afirma que o interessante em Marx é a análise do capitalismo a partir de uma perspectiva que o considera sempre em movimento de expansão dos seus contornos, que se chocam sempre com o limite do próprio capital. Deleuze (1992, p.2 16), apresenta algumas direções para refletirmos sobre esses movimentos, dentre elas destacamos: "os políticos ocidentais tiveram muito trabalho para construí-los, os tecnocratas para uniformizar regimes e regulamentos". Entretanto, a surpresa, segundo o estudioso, pode vir por parte das explosões entre os jovens, mulheres, em função da simples ampliação dos limites que lhe são impostos. Logo a seguir, o autor afirma que não existe um estado democrático que não tenha como objetivo a fabricação da miséria humana. Para o estudioso, o objetivo será refletir "como um grupo se transformará, como recairá na história, eis o que nos impõe um perpetuo 'cuidado"' (DELEUZE, 1992, p. 217).

Essa fabricação da miséria humana se constitui por meio do controle dos sujeitos, é uma constante, e está presente em todas as esferas de nossas vidas por meio de um exercício de poder se dá de várias formas e sempre com o objetivo de uma economia das subjetividades.Como foi mencionado no parágrafo anterior, o capitalismo se constitui pelo movimento, entretanto, limitado a ele mesmo. Diante disso, indagamos: Como resistir a um sistema "democrático" que tem como foco a perpetuação da miséria humana? O próprio Deleuze nos responde apontando que "a arte é o que resiste", ou seja, há modos de resistir a um "poder" que se organiza constante para se manter em uma posição confortável. Há modos de resistência que se constituirão a partir da explosão de um sujeito, ou através de pequenos grupos, que toquem em questões importantes para a manutenção das condições mínimas de existência dos sujeitos. São estes aspectos (relações de poder, formas de resistência, produção de subjetividades) que abordaremos neste texto, tendo como objeto de análise uma obra literária e enunciados que circularam em movimentos ocorridos no Brasil, durante o segundo semestre de 2018. Para tal, selecionamos uma obra literária que toca em questões muito significativas sobre os modos de existência/resistência: o romance Ensaio sobre a cegueira (SARAMAGO, 2008), publicado em 1995, três anos antes do autor receber o prêmio Nobel de Literatura.Ele é responsável por um incômodo significativo no leitor, proporcionando uma 
reflexão sobre questões extremamente relevantes acerca da constituição das subjetividades, que são elencadas a partir do caos instaurado em função da "cegueira branca" que atinge algumas personagens.

A súbita e inexplicável epidemia de cegueira conduz o discurso saramaguiano a uma problematização, desestabilização e a superação de princípios morais básicos tradicionalmente arraigados na sociedade. A trama gira em torno da repentina cegueira de um sujeito enquanto esperava sozinho dentro do carro o sinal abrir. Essa cegueira é definida como "um mar de leite". Ele recebe a ajuda de algumas pessoas e um sujeito se oferece para levá-lo em casa e rouba-lhe o carro. Ao ser deixado em casa pelo "ladrão", o primeiro cego é levado por sua esposa ao oftalmologista, que não encontra nenhuma lesão nos seus olhos, mas solicita alguns exames para sustentar um possível diagnóstico sobre esse caso raro. Por fim, o médico oftalmologista também é acometido pelo problema e aos poucos contamina todos os seus pacientes, transformando a doença em uma epidemia. Todos tomados por ela são isolados em um manicômio abandonado, porém, a única pessoa que não contraiu a cegueira é a mulher do médico, que esconde esse fato dos demais, exceto do marido. Nesse ambiente passarão por diversas situações em que o instinto se sobreporá à razão e à dignidade humana. Após certo tempo, os cegos, já vivendo fora desse espaço de exclusão, enfrentam a carência da cidade que fora saqueada pelos demais cegos que não foram encaminhados para esse espaço. Conforme a cegueira chegou repentinamente, aos poucos se ela se foi e a "normalidade" é retomada.

Partindo das considerações apresentadas acima, o presente texto tem como objetivo proceder a uma análise alguns enunciados da trama citada, juntamente com outros selecionados de cartazes que circularam em alguns movimentos sociais brasileiros ocorridos no final do segundo semestre de 2018, atentando para questões sobre a constituição da subjetividade e sua relação com o poder e a resistência na contemporaneidade. As reflexões serão fundamentadas teoricamente na análise do discurso de linha francesa, nos estudos de Michel Foucault e Judith Butler.

\section{Poder e resistência: afinal sobre o que discutimos?}

Foucault (2006) menciona em sua aula inaugural do Collège de France que o discurso é muito mais que enunciar palavras sobre um dado assunto. O discurso não é livre, ele obedece a leis que estão fora do próprio discurso, pois a produção do discurso é "controlada, 
selecionada, organizada e redistribuída por certos números de procedimentos que têm por função conjurar seus poderes e perigos, do minar seu acontecimento aleatório, esquivar sua pesada e temível materialidade" (FOUCAULT, 2006, p. 9). Esse controle é exercido por "procedimentos de exclusão", entre os quais destacaremos inicialmente a interdição. O autor assevera que "não se tem o direito de dizer tudo, que não se pode falar de tudo em qualquer circunstância, que qualquer um enfim, não pode falar de qualquer coisa” (FOUCAULT, 2006, p. 9). Deparamos assim com três modos de interdição, são eles: "tabu do objeto", a interdição sobre o tema do discurso; o "ritual de circunstância", segundo o lugar ocupado pelos sujeitos, temos um determinado ritual que deverá ser obedecido; e "direito privilegiado e exclusivo do sujeito que fala", de acordo com a situação em que o sujeito se encontra, o discurso será ou não aceito. Foucault (2006, p. 9) afirma que "temos aí o jogo de três tipos de interdições que se cruzam, se reforçam ou se compensam, formando uma grade complexa que não cessa de se modificar".

Nesse momento, questionamos: se os discursos são controlados, o que autoriza e legitima os discursos de ódio e intolerância na contemporaneidade brasileira? Por que houve um "aparente" silenciamento deles e agora nos deparamos com a sua retomada?

Para refletirmos sobre essas questões, partiremos de um sujeito constituído pela historicidade trazendo aspectos do funcionamento discursivo que apontam para o que o subjetiva, ou seja, "trata-se de um sujeito não fundamentado em uma individualidade, em um "eu" individualizado, e sim um sujeito que tem existência em um espaço social [...], em um dado momento da história e não em outro" (FERNANDES, 2005, p. 34).

Sendo o sujeito constituído por uma exterioridade e por relações de poder/saber, Foucault (1995, p. 231) menciona que seu objetivo "foi criar uma história dos diferentes modos pelos quais, em nossa cultura, os seres humanos tornaram-se sujeitos." Seu trabalho abordou três modos de transformação de seres humanos em sujeitos. O primeiro modo envolvia a constituição do sujeito "produtivo, do sujeito que trabalha, na análise das riquezas e na economia" (FOUCAULT, 1995, p. 231). Em um segundo momento, estudou a constituição do sujeito a partir das relações com outros sujeitos, no caso "o louco e o são, o doente e o sadio, os criminosos e os "bons meninos" (FOUCAULT, 1995, p. 231). Por último, pesquisou o modo como o indivíduo se torna sujeito, ou seja, nesse estudo, ele abordou como o sujeito se reconhece na sexualidade. As considerações provenientes dessas pesquisas ajudam a compreender a dinâmica que envolve a questão “quem somos nós?”, bem como a pensar outras questões. 
Michel Foucault (2004) define o objetivo do que denomina de uma "Filosofia Analítica da Política" que consistirá em tornar visível aquilo que é tão íntimo de nós que se tornou, de alguma forma, imperceptível. A tarefa tem como objetivo tecer uma analítica sobre o exercício do poder. Assim, somos constituídos por relações de poder que perpassam todas as nossas relações e não englobando uma totalidade, mas se fazendo presente em todos os lugares. Denominamos poder como estratégias específicas e complexas que perpassam uma dada sociedade. Ele se faz presente por meio de inumeráveis pontos e de relações moventes. Segundo Foucault, só existe o poder a partir do momento em que podemos resistir a esse poder e essa resistência se constitui de variados modos.

A resistência não se encontra em uma relação exterior ao exercício de poder. O poder está vinculado a uma rede vasta de relações, consequentemente, as probabilidades de resistência também se apresentam com variadas possibilidades, assim, "a resistência se move para a pluralidade. Torna-se, dessa forma, uma multiplicidade de acontecimentos possíveis, improváveis, espontâneos, planejados, violentos, irreconciliáveis, mas que, de qualquer forma, só podem se dar no campo estratégico das próprias relações de poder" (FOUCAULT, 2007, p.88).

Alguns exemplos de resistência emergem da obra foucaultiana, como, por exemplo, em Vigiar e punir (2007a), quando menciona que diante do poder punitivo do soberano não era incomum a recusa e a revolta. No que tange ao espetáculo do suplício, era muito comum as seguintes práticas:

[...] o impedimento de execuções consideradas injustas, a obtenção forçada do perdão para um condenado arrancado pela multidão das mãos do carrasco, eventualmente a perseguição, o assalto e até mesmo a morte dos executores, isso sem contar as práticas dispersas no ritual, tal como maldizer os juízes e fazer tumulto na hora da sentença (FOUCAULT, 2007a, p. 209).

Outros exemplos podem ser encontrados nas "vidas breves" que Foucault habitualmente observava em suas pesquisas, nos arquivos do internamento do Hospital Geral e da Bastilha; entre eles, mencionamos notícias de vidas "desregradas" que se davam por meio de queixas, denúncias, ordens e relações, que tratavam de sujeitos marginalizados, tais como: monges vagabundos, soldados desertores, mulheres espancadas e outros. Subjetividades desconsideradas por muitos, mas que por motivos variados foram encontradas pelo "olho" do poder que, ao menos por pouco ou determinado período, foi objeto de atenção.

Assim, o exercício do poder se articula por meio de um funcionamento que é da ordem da guerra. Fundamentado em lutas constantes, em variadas situações perpassadas pela 
violência, que, ao mesmo tempo, legitimam mecanismos de resistência, como observaremos a seguir.

\section{O discurso como modo de existência/resistência}

Só há poder a partir da possibilidade de resistência. Assim, como o poder tem sua articulação possibilitada pelo discurso, a resistência também se dá na ordem discursiva. A resistência é um posicionamento dos sujeitos que pode se materializar através de ações externas efetivas, ou simplesmente ser proveniente de um processo reflexivo que, por motivos provenientes do próprio funcionamento discursivo, não poderá ser externalizado, como afirma Foucault (2006). Com o objetivo de refletirmos sobre a constituição da subjetividade, as relações de poder e de resistência que perpassam os discursos tomados para análise, destacamos os primeiros fragmentos do romance saramaguiano:

[...] quando eles me virem neste estado perceberão logo que estou mal, metem-me numa ambulância e levam-me ao hospital, de certeza que há hospitais só para cegos, um mais não lhes faz diferença, depois tratam-me da perna, curam-me, ouvi dizer que é o que se faz com os condenados à morte, se têm uma apendicite operam-nos e só depois é que os matam, para que morram com saúde, cá por mim, se quiserem, podem depois tornar a trazer-me para aqui, que não me importa (SARAMAGO, 2008, p. 77).

Cheguem-se para trás, isto pega-se. Os soldados recuaram, medrosos, mas continuaram a olhar a poça de sangue que lentamente se espalhava pelos intervalos entre pedras miúdas do passeio. Achas que o gajo está morto, perguntou o sargento, Tem de estar, apanhou com a rajada em cheio na cara, respondeu o soldado, agora contente pela óbvia demonstração da sua boa pontaria (SARAMAGO, 2008, p. 81).

O medo lá fora é tal que não tarda que comecem a matar as pessoas quando perceberem que elas cegaram, Aqui já liquidaram dez, disse uma voz de homem, Encontrei-os, respondeu o velho da venda preta simplesmente, Eram de outra camarata, os nossos enterrámos-los logo, acrescentou a mesma voz, como se terminasse um relatório (SARAMAGO, 2008, p. 120).

O sujeito discursivo ladrão reconhece suas atitudes e reflete sobre elas, no entanto, lembra-se de algo que o faz pensar que o levarão para o hospital e só depois de curado o condenarão pelos delitos cometidos. Porém, ele é brutalmente assassinado pelos policiais logo após essa reflexão. Segundo a opinião do sujeito discursivo ladrão ainda existe um "sentimento de humanidade" na sociedade; contudo, observamos que essa reflexão não se confirma tendo em vista de seu assassinato. 
Deparamos com o sentimento de compaixão: mesmo sendo um "anormal", ele merece cuidados médicos, pois está sofrendo e só poderá ser assassinado dignamente se receber atendimento. Para refletir sobre essa questão, Butler (2009) dirá que a sociedade formula códigos de inteligibilidade, isto é, mecanismos discursivos e não discursivos de reconhecimento dos sujeitos enquanto humanos. A partir desses códigos, a existência humana passa a se reger por um enquadramento, que define quais vidas devem ou não ser seguidas, ser levadas adiante.

Os "quadros" que laboram para diferenciar as vidas que podemos apreender daquelas que não podemos (ou que produzem vidas através de um fluxo contínuo de vida) não apenas organizam a experiência visual, mas também geram ontologias específicas do sujeito. Sujeitos são constituídos através de normas que, em sua reiteração, produzem e alteram os termos por meio dos quais os sujeitos são reconhecidos. Essas condições normativas para a produção do sujeito criam uma ontologia historicamente contingente, de modo que nossa própria capacidade para discernir e nominar o "ser" do sujeito se revela dependente de normas que facilitem esse reconhecimento. (BUTLER, 2009, p. 3, grifo nosso).

Esses quadros perpassam toda a formação das normas sociais, sendo que a escritura das leis e a ética serão o que propicia o processo de identificação dos sujeitos, que é constituído por essa configuração "categorizada" das existências. Por isso, o nazismo estabeleceu um cenário normativo que isolou e posteriormente dizimou populações inteiras, e a sociedade contemporânea se organiza de modo a destacar a dignidade de certas vidas e remover do espectro a existência de outras.

Não à toa, mesmo na presença do sistema internacional de proteção aos direitos humanos, estabelecido em 1945, e dos ordenamentos jurídicos internos, matanças continuam a acontecer, não raro direcionadas a conjuntos de sujeitos que estão à margem do enquadramento socialmente estabelecido. O próximo fragmento reverbera as considerações de Butler (2009).

Perante esta situação, o Governo não teve outro remédio que fazer marcha atrás em acelerado, ampliando os critérios que estabelecera sobre lugares e espaços requisitáveis, do que resultou a utilização imediata e improvisada de fábricas abandonadas, templos sem culto, pavilhões desportivos e armazéns vazios (SARAMAGO, 2008, p. 124).

O medo se faz uma constante na sociedade constituída por cegos. O caos se instaura e o governo é "obrigado" a ampliar os espaços destinados aos cegos, há uma necessidade pungente de controle dos corpos, que deverão ser classificados de acordo com a presença ou 
não da cegueira. Os sujeitos são classificados e ordenados levando em consideração aquilo que os constitui.

Os discursos estão fundamentados no exercício de poder e saber sobre os corpos com o objetivo de normatizar a cegueira e, consequentemente, a subjetividade. A instabilidade que constitui a subjetividade se fundamenta em discursos perpassados pelo medo do desconhecido que contribui para a instauração de situações que trazem à tona a constituição dos sujeitos. $\mathrm{Ou}$ seja, o que deveria ser negado em termos de subjetividade, escapa ao controle e insurge através dos discursos de não aceitação dos sujeitos que fogem aos padrões de normalidade, aspetos que pode ser observado também no próximo fragmento.

Contra o costume, os corredores estavam desimpedidos, em geral não era assim, quando se saía das camaratas não se fazia mais que tropeçar, esbarrar e cair, os agredidos praguejavam, largavam palavrões grosseiros, os agressores respondiam no mesmo tom, porém ninguém dava importância, uma pessoa tem que desabafar de qualquer maneira, mormente se está cego (SARAMAGO, 2008, p. 144).

A convivência no manicômio, que é um espaço de segregação dos corpos, fica extremamente complicada. Em decorrência de situações que rompem com a "normalidade", a subjetividade é escancarada, ou seja, as máscaras caem e os sujeitos mostram aquilo que escondem. Assim, os sentimentos e emoções perpassados pelo ódio e a intolerância emergem espontaneamente e acirradamente em função do caos instaurado nesse espaço de convivência.

Por esse motivo, o poder atua de maneira tão eficiente na narrativa. O gerenciamento da vida humana se torna factível diante da incapacidade dos que estão subordinados em se reconhecerem, em identificarem no outro as características tão próprias da condição humana. Nesse sentido, Butler (2009) dirá que certas vidas são reféns de um processo de desrealização, quer dizer, de um procedimento multilateral, adaptável ao contexto em que essas existências estão localizadas, que lhes transmuta em seres exteriores à realidade humana - cujas vidas, irreconhecíveis, não gozam do mesmo valor.

Não se trata de uma simples entrada dos excluídos numa ontologia estabelecida, mas de uma insurreição no nível da ontologia, uma abertura crítica das questões. O que é o real? A quem pertencem as vidas reais? Como pode a realidade ser refeita? Aqueles que são irreais já sofreram, de certo modo, a violência da desrealização. Qual é, portanto, a relação entre a violência e as vidas consideradas "irreais"? A violência afeta essa "irrealidade"? Se a violência é perpetrada contra aqueles que são irreais, então, sob a perspectiva da violência, ela falha ao ferir ou negar essas vidas, uma vez que elas já foram negadas. Entretanto, elas possuem uma forma estranha de continuar animadas, e, por isso, devem ser negadas novamente (e ainda outra vez). Elas não podem ser lamentadas porque já terão sempre sido 
Karina Luisa de Freitas Assunção. O discurso como modo de existência/resistência: da literatura às manifestações nas ruas em 2018.

perdidas ou, lado outro, nunca "existiram", e devem ser assassinadas, pois aparentam continuar a viver, insistentemente, neste estado de morte. A violência se renova ante à aparente inexaustibilidade de seu objeto. A desrealização do "Outro" significa que ele não está nem vivo nem morto, mas é interminavelmente espectral (BUTLER, 2004, p. 33-34, grifo nosso).

Essas "vidas espectrais” continuam a ser perseguidas categoricamente no mundo todo, pois são assassinadas diariamente em sua voz, em sua cultura e em sua liberdade, ou, no maior extremo, em sua condição de ser vivente. Afinal, que vidas são essas? Seria impossível apreendê-las por inteiro. São mulheres, negros, pessoas LGBTI+, deficientes, moradores de rua, miseráveis etc.

Tendo em vistas as cenas destacadas, questões que perpassam a subjetividade dos sujeitos e que estavam "escondidas" são expostas e possibilitam uma reflexão mais acurada sobre a questão “quem somos nós?” proposta por Foucault (1995). Essa discussão é ampliada a seguir:

O inventário continuava, uma vez ou outra o da pistola pedia a opinião do contabilista. Que achas disto, e ele interrompia o registro para dar um parecer, dizia Pechisbe que, caso em que o da pistola comentava, Muitos assim, e não comem, ou É bom, e então o comentário passava a ser, Não há nada como lidar com gente honesta (SARAMAGO, 2008, p. 146, grifo nosso).

Os cegos recebem o pagamento pelos alimentos realizados pelos integrantes da outra ala. Nele deparamos com o enunciado "Não há nada como lidar com gente honesta" que é extremamente significativo. Os cegos exploram os outros cegos da ala contrária, exigindo algo em troca pelo alimento que chega para todos, sem nenhuma exigência de pagamento. A historicidade contemporânea se faz presente no que tange a distribuição de renda que, atualmente se fundamenta no conceito de meritocracia, ou seja, "eu tenho o mérito", enquanto o outro não tem, uma vez que não lutou eficientemente por seus objetivos. Esses discursos desconsideram aspectos relacionados com a distribuição de renda que são fundamentados em políticas públicas sustentadas pelas desigualdades sociais alicerçadas por dados discursos considerados verdadeiros. O que realmente sustenta o "direito" de uma ala cobrar pelos alimentos no romance supracitado será apresentado a seguir.

Quando entraram na camarata e tiveram de apresentar o pouco que traziam para pôr na mesa, houve quem achasse que a culpa era deles, por não terem reclamado e exigido mais, para isso é que tinham sido nomeados representantes, do colectivo. Então o médico explicou o que se havia passado, falou do cego escriturário, dos modos insolentes do cego da pistola, da pistola também (SARAMAGO, 2008, p. 147, grifo nosso). 
O "direito" dos cegos é assegurado pela "pistola", é ela que sustenta um grupo de cegos no poder e possibilita que eles explorem os demais. Deparamos com uma situação contraditória, como um cego sustenta o seu poder com uma pistola se não enxerga os demais? Esses enunciados questionam a legitimidade dos sujeitos em dadas relações de poder, pois deparamos com um grupo de cegos conduzido por cegos.

Butler (2009) questiona: o que é uma vida boa? No experimento neoliberal, em que a capacidade de consumo dita os desejos mais íntimos dos sujeitos, ter uma vida boa diz respeito ao exercício pleno dos direitos, a ter conforto, à aquisição dos bens que se almeja, à ocupação livre dos espaços sociais e à liberdade de viver longe da miséria, da fome e do medo.

Entretanto, a autora apontará para uma pungente hipocrisia e contradição nessa pergunta. Como se poderia pensar o conceito de vida boa quando milhões de pessoas não são consideradas dignas do direito à própria vida? Segundo Butler (2009), o problema das sociedades contemporâneas é que os códigos de inteligibilidade levam os sujeitos a desconhecer aqueles que não lhes são similares, isto é, provocam nos sujeitos um alto grau de não identificação com a diferença.

Em meio ao caos estabelecido e às incertezas que perpassam os sujeitos na contemporaneidade que tem a subjetividade fundamentada em verdades que são "aparentemente" inquestionáveis, mas que quando examinadas atenciosamente são contraditórias, nos interrogamos: como resistir? Acreditamos que a literatura saramaguiana apresente elementos significativos sobre as formas de resistência.

\footnotetext{
Vou contigo, disse o marido, Não, é melhor que vá sozinha, temos de saber como se está a viver agora, pelo que ouvi dizer toda a gente deve ter cegado, Então, disse o velho da venda preta, é como se continuássemos no manicómio,Não há comparação, podemos mover-nos à vontade, e a comida há-de resolver-se, não iremos morrer de fome, também tenho de arranjar roupas, estamos reduzidos a farrapos, a mais necessitada era ela, [...] Beijou o marido, sentiu nesse momento como uma dor no coração, Por favor, aconteça o que acontecer, mesmo que alguém queira entrar não deixem esse sítio, e se forem postos para fora, apesar de que não creio que tal aconteça, mas é só para prevenir todas as hipóteses, deixem-se ficar perto da porta, juntos, até que eu chegue, Olhou com os olhos rasos de lágrimas, ali estavam, dependiam dela como crianças pequenas dependiam da mãe (SARAMAGO, 2008, p. 218).
}

A resistência e a intolerância que constituem a subjetividade na contemporaneidade deverão se constituir pela identificação de nossos pares e da fragilidade que perpassa a condição humana. Ou seja, devemos exercitar o olhar para si e para o outro sem os padrões 
que sustentam a sociedade, mas apenas como sujeitos que necessitamos uns dos outros para sermos o que somos, ou seja, nos constituirmos enquanto sujeitos, como podemos observar no fragmento acima.

As imagens a seguir, retiradas de algumas manifestações realizadas em 2018, corroboram com a escrita saramaguiana:
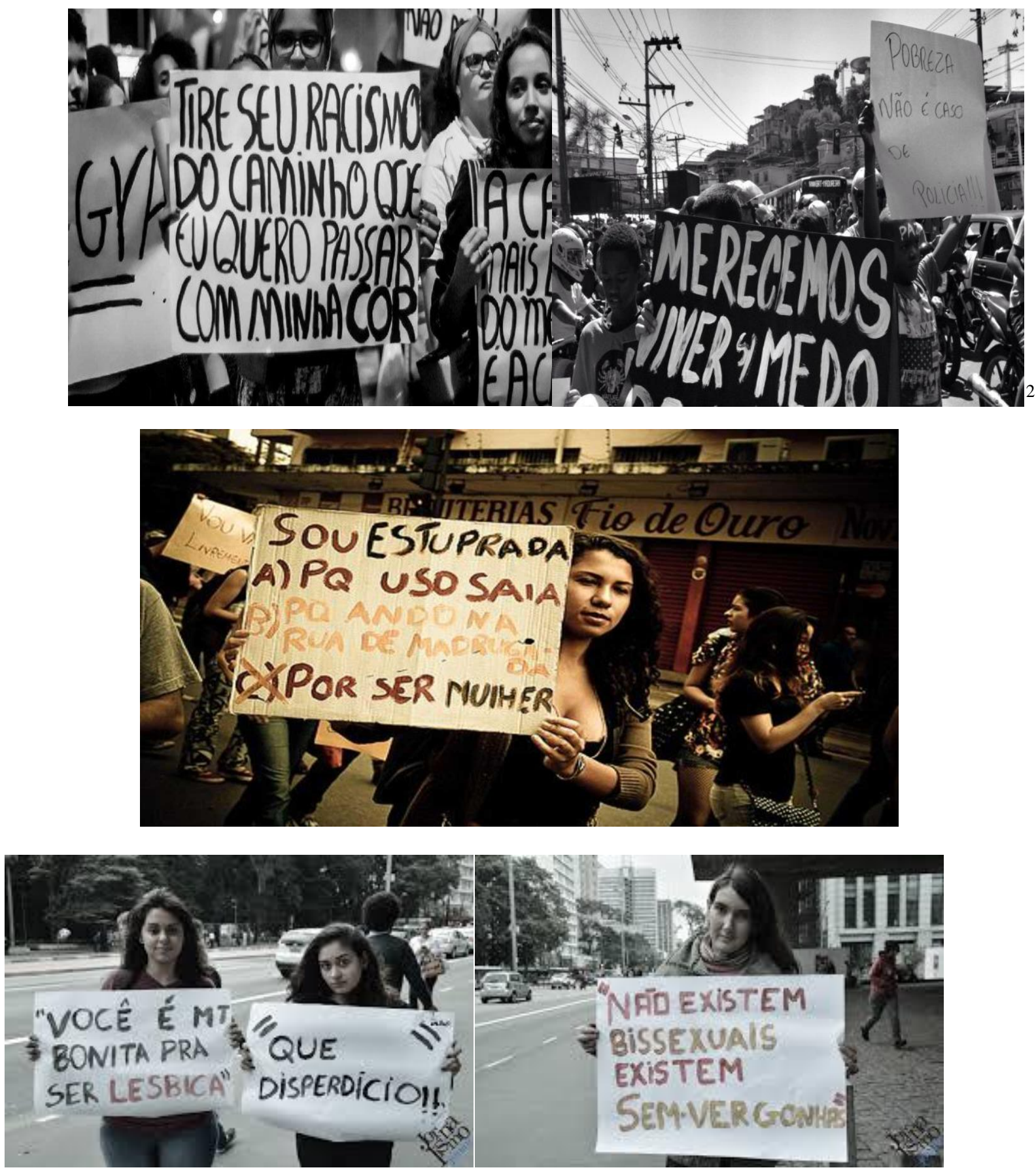

2 Disponível em: <http://jornaldesantacatarina.clicrbs.com.br/sc/geral/noticia/2017/08/o-que-gera-a-onda-decomentarios-de-odio-nas-redes-sociais-9880494.html>. Acesso em: 28 nov. 2018. 
Discursos de ódio e não aceitação incitam os sujeitos a deflagrarem variadas posturas de intolerância contra as minorias, negros, LGBT, índios, mulheres e outros. Vale ressaltar que esse movimento não está restrito ao Brasil; infelizmente, é mundial.

Por meio das redes sociais, a intolerância ganha contornos ainda não imaginados e a onda de ódio atinge a todos que não obedecem ao "padrão de normalidade" estabelecido pela sociedade. Vivenciamos um período de tentativa de silenciamento das singularidades e a propagação de uma aparente normalidade que tem como objetivo apagar aspectos da subjetividade que desagrada os detentores do poder. Nesse momento levantamos as seguintes questões: como se articula a constituição da subjetividade dos sujeitos que propagam esses discursos de ódio? Quais sentidos emergem desses discursos que defendem um "apagamento" das singularidades?

Os discursos de ódio que circulam estão fundamentados na intolerância e reverberam sentimentos reprimidos historicamente. Entretanto, são legitimados nesse momento pelos discursos fundamentados na valorização do ódio e produzidos por sujeitos que assumem um "lugar de verdade" em sua defesa. Essas produções discursivas problematizam a contradição e o antagonismo constitutivos da subjetividade, apesar de observamos uma tentativa de apagamento dessa contradição constitutiva. Os sentidos que emergem dessas materialidades discursivas destacam uma "tentativa" de manutenção da liberdade e democracia. Entretanto, eles apontam para o contrário, ou seja, a limitação de direitos dos sujeitos e a ampliação dos deveres perante a sociedade.

\section{Existir/Resistir... devir...}

O sistema capitalista está sempre em movimento e expansão, entretanto, seu limite é o próprio capital, como afirmou Deleuze (1992) a partir da leitura de Marx. Esse sistema se fundamenta em relações de poder que tem como objetivo constituir a subjetividade. Entretanto, podemos resistir e essa resistência, como o próprio estudioso afirma, deverá partir das minorias, pois ela não tem um modelo pré-determinado a ser seguido, trata-se de um processo em constante construção que reflete os posicionamentos dos sujeitos que fogem a um espaço delimitado previamente.

Estamos inseridos em uma sociedade que funciona não em uma perspectiva de confinamento, mas de controle da comunicação. Deparamos com a implantação de novas 
formas de controle que perpassam todas as instituições e chegam invariavelmente a todos os sujeitos.

Somos controlados a todo momento, mas podemos resistir, e isso se dá de variadas formas, através da arte, das manifestações nas ruas etc. Essas manifestações são ferramentas de resistência, com possibilidades de resultados que são da ordem do imprevisível. Dessa forma, é preciso "acreditar no mundo significa principalmente suscitar acontecimentos, mesmo pequenos, que escapem ao controle, ou engendrar novos espaços-tempos, mesmo de superfície ou volume reduzido" (DELEUZE, 1992, p. 222).

A escrita saramaguiana, por meio de uma narrativa utópica, e as manifestações nas ruas, em 2018, são práticas discursivas de resistência. Os sentidos desses discursos não são delimitados e controlados previamente, mas são extremamente relevantes, pois questionam as relações de poder que tem como objetivo controlar uma maioria em detrimento de uma minoria, fundamentada pelo sistema neoliberal.

Assim, podemos concluir que o funcionamento desses discursos é da ordem da guerra, como mostra Foucault ao longo de suas pesquisas. Existir/resistir as suas nuanças se faz uma constante e se fundamenta em um movimento que não temos como prever os caminhos, muito menos os resultados, uma vez que será sempre da ordem do devir. Entretanto, resistir ao poder sempre, pois só assim existiremos enquanto sujeitos constituídos historicamente.

\section{Referências}

BUTLER, Judith. Vida precária: el poder del duelo y laviolencia. Buenos Aires: Paidós, 2009.

FERNANDES, Cleudemar Alves. Análise do Discurso: reflexões introdutórias. Goiânia: Trilhas Urbanas, 2005.

FOUCAULT, Michel. O sujeito e o poder. In: RABINOW, Paul; DREYFUS, Hubert. Michel Foucault Uma trajetória filosófica. Para além do estruturalismo e da hermenêutica. Rio de Janeiro: Forense Universitária, 1995, p. 231-249.

FOUCAULT, Michel. A vida dos homens infames. In: Ditos \& Escritos IV: Estratégia, Poder-Saber. Tradução Vera L. Avellar Ribeiro. Rio de Janeiro: Forense Universitária, 2003.

FOUCAULT, Michel. A Filosofia Analítica da Política. In: Ditos e Escritos V: Ética, sexualidade, política. Tradução Elisa Monteiro e Inês Dourado Barbosa. Rio de Janeiro: Forense Universitária, 2004.

FOUCAULT, Michel. A Ordem do Discurso. São Paulo: Edições Loyola, 2006. 
FOUCAULT, Michel. Vigiar e punir. Petrópolis: Vozes, 2007a.

FOUCAULT, Michel. História da sexualidade 1 - A vontade de saber. Rio de Janeiro: Graal, 2007b.

SARAMAGO, José. Ensaio sobre a cegueira. São Paulo: Companhia das Letras, 1995.

Recebido em: 31 de outubro de 2019

Aceito em: 1 de dezembro de 2019 